\title{
SOME STATISTICS OF MYOPIA IN SCHOOL CHILDREN; WITH REMARKS THEREON \\ BY
}

\author{
ERNEST THOMSON, M.D.
}

OPHTHALMIC SURGEON TO THE COUNTY OF LANARK EDUCATION AUTHORITY; FORMERLY SURGEON, GLASGOW EYE INFIRMARY.

MYOPIA is a mysterious disease, perhaps as mysterious as glaucoma in the matter of aetiology.

We talk of school myopia, hereditary myopia, congenital myopia. What, for instance, is meant by school myopia? This term seems to have no very precise meaning, since, while admitting the common onset of myopia during the educational period, one finds cases in which there is distinct heredity, and others in which there is no trace of it. If there is no hereditary tendency to actual myopia in any given case, what is the precise causative factor in that case? Is there, indeed, any one factor? The possible factors are numerous enough; convergence strain, bad lighting, bad hygiene, physical strain (Edridge-Green), weakness of the sclerotic, and so on. But to what extent each or any of these or other factors may be responsible for the onset of myopia no one is able to say. It has been held that the essential cause is weakness of the sclera caused by tubercle. To me this is rather an attractive hypothesis, for although it has not yet been possible to correlate my myopia statistics with the incidence of tubercle in the various districts in the County of Lanark, there is at least a suggestion in them pointing in the direction of parallelism between myopia incidence and a tendency to "strumous" affections.

Meantime, it is intended merely to emphasize certain facts which my statistics seem to bring out, not to discuss various theories of the aetiology,

The school area with which I have to deal is a wide one, including as it does the County of Lanark exclusive of certain districts, and, of course, exclusive of the City of Glasgow. Lanark is a large and populous county in which agriculture, coal mining, and industry are much mixed together. It is comparatively easy to define the larger urban districts and to say that here the population is purely industrial, but it is less easy to define the country districts in many of which there are coal pits and small towns in which industries are carried on. Nevertheless it is possible to "make a rough division of all the districts into urban and rural and also to pick out certain of them which may be called urban, rural, and mixed respectively.

(1) It has at various times been stated that myopia is less common in the country than in the town, that it is a disease of the educated, of those who use their eyes largely at close range. The 
statement has been made that the country dweller is not prone to myopia because he uses the eyes for distance. Yet my figures, small and imperfect as they are, do not lend support to this view. They show that in so far as concerns the children in the County of Lanark who apply for treatment under. the voluntary scheme of the Education Authority, those attending rural schools present a higher percentage of myopia and myopic astigmatism in one or both eyes than those attending urban schools. The words italicised must be carefully noted, for the war has prevented the natural expansion of the Authority's scheme, which, under normal conditions, would doubtless ere this have, reached out to cover an enquiry into the visual conditions of all the school children in the County. That this will eventually be done I have very little doubt. Meantime, the figures may be taken for what they are worth.

During the period from August, 1914, to July, 1917, I personally examined 3,249 children. Of these, 612 had myopia or myopic astigmatism in one or both eyes, that is 18.8 per cent. But, if the districts are separated into two main classes, urban and rural, it is found that of 2,655 urban cases 468, or 17.6 per cent., were myopic; while of 594 rural cases 144 or $24^{\circ} 2$ per cent. were myopic. The disproportion between the numbers of urban and rural cases examined is a weak point statistically, yet the calculation has been made for each year separately as well as in the aggregate, and the proportion of myopia has been consistently higher in the rural group.

On account of the difficulty of deciding in certain areas whether these should be classed as urban or rural, the figures have been worked out in another way. Certain districts difficult to classify were omitted from the calculation. Four districts were selected as practically purely urban industrial, three as practically purely agricultural, and four as mixed agricultural, mining and industrial. In the main classification into urban and rural, the second and third groups of selected districts (see table), belong to the rural division.

Continuing to deal with these selected groups of districts, it was found that in the urban group 1,561 cases gave 269 myopias, or $17 \cdot 23$ per cent. In the agricultural group 229 .cases gave 47 myopias or 20.52 per cent. In the mixed group 365 cases gave 97 myopias or 26.57 per cent. (see table). In all cases the figures refer to myopia or myopic astigmatism in one or both eyes. Except in complicated cases refraction has been estimated by retinoscopy under atropin and cocain.

From these figures it is probably not unreasonable to conclude that in the County of Lanark the children of agriculture are not less myopic than the children of industry, and that it looks as if the children of the miner are more subject to myopia than those of the other two classes. Here is wide scope for the investigation of the 
hygiene of the school and of the home (the latter concerning parent as well as child), the lighting conditions of both, and the prevalence of particular diseases, especially tubercle. As has been remarked previously, the figures are pointers only, and may perhaps suggest statistics from other workers in the same field.

If the conclusion here indicated be admitted, we are still left to ponder upon the questions of heredity, of home and school environment, and of other possible factors, as causes of myopia.

It has not been possible, in the meantime, to investigate the presence or absence of heredity in each case, but undoubtedly the part played by it is very uncertain. Cases of high and dangerous myopia occur in children whose parents and other accessible relatives are not myopic, while, in others, there is undoubted heredity. It has been suggested, I think, that weakness of the sclerotic is the transmitted factor in cases where the parents are not themselves myopic. Is the cause of the weakness tubercle, syphilis, or consanguinity?

Home and school environment is a very large question, also open for investigation in the future which is coming to us with the end of the war and the consolidation of educational authorities. Undoubtedly, the home environment of some of the workers in agricultural and mining districts in Scotland is very bad indeed. On the other hand, nothing could well be worse than the lighting conditions in some of the urban schools.

The following family history illustrates very well the impossibility of fixing the blame on either heredity or school work in a given case. This family apparently has a hereditary tendency to myopia, yet there is no myopia in the parents; or ascendants generally, so far as is known to the mother. On the other hand, James L. had 20 dioptres of myopia at 5 years of age.

James L., aged 5 years. Myopia approximately $20 \mathrm{D}$. in each eye. Fundus changes incommensurate with the amount of myopia. At 7 years the V. was R.E. -16 D. $=5 / 24$. L.E. -18 D. $=5 / 60$. Alternating convergent squint. Child backward and shy, but improving in these respects.

John L., aged 10 years. Right eye emmetropic. Left eye myopic $4 \mathrm{D}$. Convergent squint, amblyopia. Formerly had acute phlyctenular disease.

Grace L., aged 12 years. Right eye myopic astigmatism. Highest meridian $11 \mathrm{D}$. Left eye myopic $14 \mathrm{D}$. Marked fundus chänges. Eventually V.R. 5/6, L. 5/18. No squint.

In this family the mother was quite intelligent, and had herself sought for a hereditary cause and found none whatever. Out of 6 eyes in 3 children 1 eye entirely escaped myopia, although the mean of the other 5 eyes was no-less than $13 \cdot 8 \mathrm{~B}$, while the mean of the ages was only 9 years. 
In addition to the various fields of statistical enquiry which have been here suggested, and which it is possible in the future I may be in a position to enter, there is another, the outlines of which are still vague. It has been borne in upon me in the course of my dealings with children belonging to different districts of the county, in taking spectacle frame measurements, that there is some evidence of local variation in the type of face and skull, as shown by a predominant type of nose, and perhaps also of interocular width, and of length from ear to orbit margin, in children of similar ages. I do not know what bearing this might have if worked out in careful detail. It is certainly the fact that in the mining districts especially there is a non-British element. By no means all of these people retain their original names. John Smith may quite well have been born, let us say, Kalewski, a fact which renders investigation more difficult than otherwise it might be.

(2) The next point taken up statistically is the mean myopia in the different districts. This has been calculated in the selected districts already referred to, and tabulated along with the percentage of myopia (see Table). The procedure adopted was to add together the highest meridians of myopia in all the myopic children examined in each district, and to divide the sum by the number of myopic children, thus obtaining the mean highest meridian. This was done separately for each eye. In cases of anisometropia, one eye myopic, the other non-myopic, the non-myopic (including mixed astigmatism) eye was left out of the addition, but counted one in ascertaining the mean. For example, to take an imaginary district with only four children :

\begin{tabular}{|c|c|c|}
\hline & $\begin{array}{l}\text { Highest } \\
\text { Right } \\
9 \\
\text { Mixed } \\
0.5 \\
\text { E }\end{array}$ & $\begin{array}{c}\text { Meridian. } \\
\text { Left } \\
7 \\
4 \\
\mathrm{H} \\
1 \cdot 0\end{array}$ \\
\hline & 4) $9 \cdot 5$ & 4) $12 \cdot 0$ \\
\hline ean myopi & $2 \cdot 37$ & $3 \cdot 0$ \\
\hline
\end{tabular}

The result of this investigation (see Table) does not seem to point to any striking difterence between the mean myopia in the urban and rural districts respectively. One very decidedly rural district (Abington, etc:), certainly has a higher mean than any other, though Lanark, a mixed district, is not very far behind.

There is a quite noticeable tendency for the mean myopia to be higher in the right than in the left eye. In each group of districts the mean of means is higher for the right eye, but the difference is more obvious in looking at the results for the individual districts. 
In only two out of the eleven has the left eye a higher mean than the right. If all the means be added together and divided by three the right eye shows $4 \cdot 04$ and the left $3 \cdot 53$.

One is probably justified in saying that there is no evidence of any particular difference in the type of myopia in the urban and rural districts respectively. Neither has a monopoly of the high type. In actual practice I have found this type scattered about impartially, so far as I could judge, and the statistical method at least confirms this impression. It is to be noted nevertheless that on balance the urban districts have a tendency to a lower mean than the other two types of district, though in view of the disparity of the numbers of cases seen in the three types of district one hesitates to trust the figures too far.

The apparent tendency, one can put it no higher, for the myopia to be greater in the right eye than in the left is interesting and suggestive, nothing more. Further statistical enquiry is necessary before such predominance could be proved. Here, again, I would appeal to other workers. The whole subject of myopia in children demands immense figures obtained by trained oculists and these figures will in time be forthcoming.

(3) Squint in myopic children.-It is commonly accepted that divergent strabismus is the ordinary type of squint in myopia. In his article "The Cause and Prevention of Myopia " (Lancet, Jan. 26, 1918), Edridge-Green makes the following statement: "In convergence excess, as in convergent strabismus or internal squint, myopia is not produced and convergent strabismus is almost exclusively found in hypermetropic eyes." In this short statistical report I am not concerned to discuss this or that theory of myopia, but the latter part of the statement just quoted is so contrary to the facts as I have observed them for children, that it is advisable to set down my own statistics. These extend over a somewhat longer period than those already given for myopia itself. The records of 790 myopes have been analysed, and may be synopsized as follows:

Total squints noted 65 , doubtful 9 .

Divergent Squint

$$
\left.\begin{array}{lr}
\text { Left eye } & 14 \\
\text { Right }, & 11 \\
\text { Alternating } & 2
\end{array}\right\}=27 \text {, plus } 2 \text { doubtful, ... }
$$

Convergent Squint

$$
\left.\begin{array}{lr}
\text { Left eye } \cdot & 20 \\
\text { Right } & 16 \\
\text { Alternating } & 2
\end{array}\right\}=38 \text {, plus } 7 \text { doubtful, ... }
$$

$\begin{array}{llllll}\text { Percentage of divergent taken as } 29 & \ldots & \ldots & \ldots & 3 \cdot 67\end{array}$

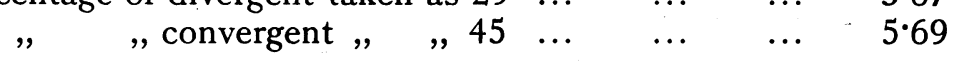


If the doubtful cases be omitted the excess of convergent over divergent squints will be a little smaller.

It may be suggested that I have mistaken the effect of the angle gamma for convergent squint. One might grant the possibility for the cases recorded as doubtful, but to one who is aware of the extence of the angle gamma a mistake is not very probable in the others. I think it must be accepted that in the 790 myopic school children (some myopic in only one eye, as has been stated already), convergent squint was not only not less frequent, but was actually more frequent than divergent. I am free to admit that my records of exophoria are not trustworthy, and therefore they have not been stated.

The preponderance of left eye squint will be noted. This is quite in harmony with what I find, statistically, to occur when convergent squint is noted over all conditions of refraction. I am incapable at the moment of giving the exact figures, but, basing upon an approximate calculation taken over two years statistics, I should place left squints at 53 per cent., right squints at 39 per cent., and alternating squints at 8 per cent.

It appears, then, as regards these children that (1) convergent squint in myopia is commoner than divergent, (2) In convergent squint, under all conditions of refraction taken together, and including the specially investigated case of myopia and myopic astigmatism, the left eye is involved more often than the right eye. Whether or not this is the common experience I am unaware.

Leaving on one side the question as to which eye is involved more often, which may be regarded as "another story," is not the excess of convergent over divergent squint in myopic children rather what one would expect? It is a common observation that the number of squinting adults is relatively smaller than that of squinting children. If every (convergent) squinting child grew up with a squint 27.4 per cent. of people on the street might be squinters! A great many convergent squints become cured as regards the deformity. It is easy to suppose that in myopic children a convergent squint often gives place, as in other conditions of refraction, to approximate orthophoria. This ultimately changes to divergence, thus accounting for the presumed greater number of divergent squints in myopic adults.

In any case, and this is the main point, the statement of EdridgeGreen, which probably voices a common opinion, seems open to question in view of the statistics which have been given here; and if the statement as applied to children proves to be as incorrect as my results seem to show, then it is useless as part of the foundation for an argument as to the aetiology of a disease which usually commences in childhood.

I trust it may be possible for some other workers to confirm or 
refute the few results given in this brief record, and to carry forward investigations on myopia in school children in various localities which may throw light on the aetiology of this disease. The field is a large one and up to now has not been explored, so far as I know, on any great scale in this country. Expert inspection of the eye conditions of all school children at entry is the first desideratum. Ordinary Medical Inspecţion, by a School Medical Officer who has not the training of an oculist, is of comparatively little service. Systematic and comprehensive enquiry into home and school conditions is also most important, and it would be surprising if two such sets of statistics on a large scale did not afford mutual illumination.

TABle SHOWING THE PERCENTAGe OF Myopia AND THE MEAN OF THE HIGHEST MERIDIANS IN CERTAIN SELECTED DISTRICTS of THE COUNTY OF LanaRK.

\begin{tabular}{|c|c|c|c|c|c|}
\hline \multirow[t]{2}{*}{ District. } & \multirow{2}{*}{$\begin{array}{l}\text { Children } \\
\text { examined. }\end{array}$} & \multirow{2}{*}{$\begin{array}{l}\text { Per cent. } \\
\text { Myopic } \\
\text { Children. }\end{array}$} & \multicolumn{2}{|c|}{ Mean of Highest Meridian. } & \multirow{2}{*}{$\begin{array}{l}\text { Nature of District with } \\
\text { respect to Occupations. }\end{array}$} \\
\hline & & & R. & L. & \\
\hline \multirow{5}{*}{$\begin{array}{ll}\text { Coatbridge } & . . \\
\text { Motherwell } & . . \\
\text { Rutherglen } & . . \\
\text { Shettleston } & . .\end{array}$} & 481 & 18.08 & $4 \cdot 16$ & 3.48 & \multirow{5}{*}{$\begin{array}{l}\text { Almost purely urban. } \\
\text { Almost purely urban. } \\
\text { Almost purely urban. } \\
\text { Almost purely urban. }\end{array}$} \\
\hline & 419 & 15.03 & $4 \cdot 18$ & 3.72 & \\
\hline & 291 & $17 \cdot 86$ & 3130 & $2 \cdot 88$ & \\
\hline & 370 & $18 \cdot 10$ & 3.73 & 3.29 & \\
\hline & 1,561 & $17 \cdot 23$ & $\begin{array}{l}3 \cdot 84 \\
\text { Mean }\end{array}$ & $\begin{array}{c}3 \cdot 34 \\
\text { of Means. }\end{array}$ & \\
\hline \multirow{4}{*}{$\begin{array}{l}\text { Abington, } \\
\text { Biggar and } \\
\text { Carnwath } \\
\text { Cadder } \\
\\
\left.\begin{array}{l}\text { Strathaven } \\
\text { and } \\
\text { East Kilbride }\end{array}\right\}\end{array}$} & 62 & 27.41 & 5.48 & $5 \cdot 37$ & \multirow{4}{*}{$\begin{array}{l}\text { Almost purely agricul- } \\
\text { tural. } \\
\text { Almost purely agricul- } \\
\text { tural } \\
\text { Purely agricultural. }\end{array}$} \\
\hline & 85 & 16.47 & $3 \cdot 30$ & $1 \cdot 35$ & \\
\hline & 82 & 19.51 & $3 \cdot 86$ & $2 \cdot 75$ & \\
\hline & 229 & 20.52 & $\begin{array}{l}4 \cdot 21 \\
\text { Mean }\end{array}$ & $\begin{array}{c}3.15 \\
\text { of Means. }\end{array}$ & \\
\hline \multirow{5}{*}{$\begin{array}{l}\text { Carluke } \\
\text { Lanark } \\
\text { Lesmahagow ... } \\
\text { Shotts } \quad . .\end{array}$} & 59 & $35 \cdot 59$ & $4 \cdot 42$ & $3 \cdot 87$ & \multirow{5}{*}{$\begin{array}{l}\text { Agriculture, Mining, } \\
\text { Manufacture. } \\
\text { Agriculture, Mining, } \\
\text { Manufacture. } \\
\text { Agriculture and Mining } \\
\text { Agriculture, Mining, } \\
\text { Iron smelting. }\end{array}$} \\
\hline & 119 & $31 \cdot 92$ & 4.93 & $4 \cdot 81$ & \\
\hline & 40 & 30.00 & $4 \cdot 20$ & $4 \cdot 75$ & \\
\hline & 147 & $17 \cdot 68$ & $2 \cdot 94$ & 3.00 & \\
\hline & 365 & $\begin{array}{l}26 \cdot 57 \\
.\end{array}$ & $\begin{array}{l}4.12 \\
\text { Mean }\end{array}$ & $\begin{array}{c}4 \cdot 10 \\
\text { of Means. }\end{array}$ & \\
\hline
\end{tabular}

I have not ventured to bring forward statistics bearing upon treatment. In a voluntary scheme it is not possible to follow up every child until he or she leaves school. Even when the myope is 
caught young and the parents are willing and intelligent people, the process of following the case through to the end of school life involves years. In the case of Lanarkshire children under my care a sufficient length of time has not yet elapsed for the statistical record of children treated and followed through to be of much value. Further, owing to the present voluntary nature of the scheme very many cases have only been examined late in school life and have escaped from observation after the first or second attendance. We have as yet no special myopia schools in the County of Lanark apart from Glasgow. It is to be hoped that these will come later on when the new education authority gets fairly to work.

\title{
NOTES ON A CASE OF ANOMALOUS INNERVATION OF THE LEVATOR PALPEBRAE SUPERIORIS (LEFT)
}

\author{
H. Somerville Martyn, M.A., M.B., Surgeon-Lieut. R.N., \\ ASST. GLASGOW EYE INFIRMARY.
}

A. E. C., aged 44, A.B., admitted to P.H. in June, 1918, was found on examination of his extrinsic muscles, to present the following abnormality, viz., that on looking down and to the right the left levator palpebrae superioris was thrown into action as represented in Fig. 1.

The extraordinary aspect called for verification by repeated tests, and on every occasion the same appearance presented when looking in the direction stated. More detailed examination revealed, further, that on extreme rotation to the right, on a level with the eyes, the left levator came into action and increasingly so, as the eyes were rotated to the right. This is represented in Fig. 2.

The position of the left upper lid was then more minutely investigated when the eyes were turned in the directions mentioned below, with the following results :

\section{Direction of Eyes.}

1. To the right and up.

Up. 2. Straight up.

3. Up and to the left.

4. To the right.

Level. 5. Straight ahead.

6. To the left.

7. On convergence.
Position of Left Upper Lid.

Similar to the right.

Similar to the right,

Similar to the right.

Distinctly elevated

Similar to the right.

Slightly lower than right.

Similar to the right. 